\title{
Ranking of Factors Influencing Safey Performance in Construction
}

\author{
Cinu Mathew \\ M.tech, Department of Civil Engineering \\ Toc H Institute of Science and Technology \\ Kerala, India
}

\author{
Annie Sonia Xavier \\ Asst. Professor, Department of Civil Engineering \\ Toc H Institute of Science and Technology \\ Kerala, India
}

\begin{abstract}
Construction sector is considered to be one of the largest sector and it have a large quantum of human resource. Since the sector have greater number of humans involves, it is important that safety should be enhanced at each and every stage. It is quite usual in construction sites to have incidents and accidents. These usually lead to losses which can direct or indirect, financial or non-financial. It is hence important to identify the causes of accidents. This journal reviews on the factors affecting safety performance in construction and ranking of the identified factors using questionnaire survey.
\end{abstract}

Keywords—Humanitarian; incident; accident; performance

\section{INTRODUCTION}

The construction industry is one of the most hazardous industrial fields having very high accident rates compared to other sectors. Construction projects differ in size, duration, objectives, environment, uncertainty, complexity, deadlines, financial intensity, organization structures, and some other dimensions. Construction sites are in a constant state of change; its dynamic, temporary, and decentralized nature indicates frequent inspections. Construction site safety is of utmost importance due to nature of construction industry. The importance of construction safety arises from humanitarian consideration. The losses during an accident can be financial such as loss of working hours, medical expenses etc and nonfinancial such as health condition, loss of lives etc. Since a large quantum of labor force is used in construction, their safety is of prior importance. The causes of accidents or incidents in construction are personnel factors and technical factors. The personnel factors are the steps that are to be taken by each individual in the sites. Technical factors are the steps taken by the professionals in reducing the accidents. Since there are many causes of accident and that results from the factors that occur in the construction environment, these factors in favorable circumstances, can significantly increase the probability of hazard becoming operational and leading to an occupational accident. The main intention in measuring safety and health performance is providing information on the progress and current situation of site activities to control safety and health risks. Moreover, measurement will be only considered effective when it is reporting on the risk levels and also investigating the reason of exposing to current risk level. Then, the corrective actions will be taken to improve overall project performance ultimately.

\section{LITERATURE REVIEW}

Asgard $\mathrm{T}$ et.al.(2019) assessed the early phases in construction project management and its influential in the scenary of safety. The research find out that three main challenges to health and safety in the early phases of construction projects were lack of competency, lack of prioritization and lack of consequences. They also put forward the measures to reduce accidents as educational institution, construction client and public authorities to play there part to improve the situation

Mohammadi A et.al (2018); described in detail about accident, its causes and measures to minimise it. Safety and health is stated as the degree to which the general conditions promote the completion of a project without major fatalities or injuries. Measurement of safety is primarily look at the amount of accidents occur during construction period. Construction works are well known as one of the most dangerous and risky activities throughout the world because large amount of people are being killed and injured every year.

Hola B et.al.(2017) explains the factors that affect accidents in construction sites.. In this study the factors affecting safety are divided into three groups due to their location in the construction work environment and its surroundings. Correlation analysis was done to find the relation between the value of construction and assembly production and accident rate in construction industry.

Mahmoudi S et.al (2014) suggested the need of a comprehensive and simple to administer tool to continuously assess and promote its health and safety performance. In this study seven main elements were determined from standards and guides and factors affecting these elements are found out from literatures. The relative importance of each element and its relative factors was calculated at organisational and project level.

Tam C M (2004) examined the status of safety management in the Chinese construction industry. Also risk prone activities on construction sites and factors affecting safety in construction sites are also discussed. The main factors affecting safety performance includes poor safety awareness, lack of training, poor reluctance of input resources of safety and reckless operations. The research also proposes suggestions for improving safety performance of a construction project.

Sawacha E et. al. (1999) investigated the impact of historical, economical, psychological, technical, procedural, organizational and environmental issues are considered for its effect or link with the safety level in the sites. The historical factors are identified based on the background and characteristics of individual, economic factors by monetary values, psychological factors based on safety behavior, 
technical and procedural based on training and handling of safety equipment, and organizational and environmental factors based on safety policy.

\section{METHODOLOGY}

A thorough literature review was done to identify the factors affecting safety performance. Initially 24 factors affecting safety performance was identified. From the identified factors, the most relevant 17 factors were chosen according to expert reviews and interviews. The factors thus are ranked based on questionnaire surveys.

\section{DATA ANALYSIS}

The literature survey identified most influential safety attributes affecting the construction industry. In this study it ranks the factors based on both their importance and its frequencies. This study also includes both qualitative and quantitative research techniques. The qualitative study helps to collect the safety attributes and quantitative study is done by a questionnaire survey base on three point likert scale. The questionnaire survey consists of ranking based on importance and frequency in likert scale. The three point likert scale is converted to five point likert scale based on fuzzy logic. The decision table used for this purpose is as shown in the figure and the conversion of likert scale to crisp value is shown in table 1 .

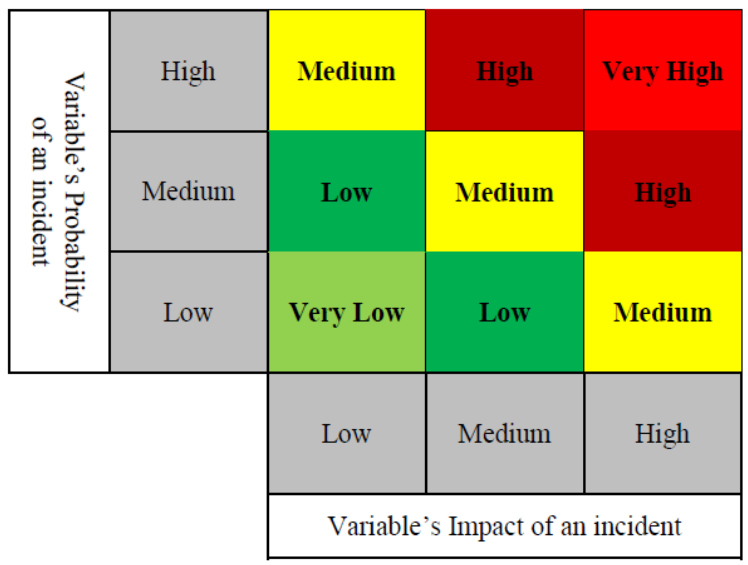

Fig 1: Decision table of variable's effect on Safety Performance

TABLE I. RANKING OF FACTORS

\begin{tabular}{|l|l|l|}
\hline Linguistic terms & Fuzzy numbers & Crisp values \\
\hline Very low (VL) & $(0,0,0,0.3)$ & 0.075 \\
\hline Low (L) & $(0,0.3,0.3,0.5)$ & 0.275 \\
\hline Medium (M) & $(0.2,0.5,0.5,0.8)$ & 0.500 \\
\hline High (H) & $(0.5,0.7,0.7,1)$ & 0.725 \\
\hline Very high (VH) & $(0.7,1,1,1)$ & 0.925 \\
\hline
\end{tabular}

Relative importance index (RII) is used as it allows identifying most of the important criteria based on the replies of participants.

$$
\begin{aligned}
R I I & =\frac{\sum W}{945 * n_{5}+.725 * n_{4}+.5 * n_{3}+.275 * n_{2}+.075 * n_{1}} \\
& =\frac{.925 * N}{.925}
\end{aligned}
$$

Where;

low

$\mathrm{n}_{1}$ : number of respondents corresponding to very

$\mathrm{n}_{2}$ : number of respondents corresponding to low $\mathrm{n}_{3}$ : number of respondents corresponding to medium $\mathrm{n}_{4}$ : number of respondents corresponding to high $\mathrm{n}_{5}$ : number of respondents corresponding to very

high

$\mathrm{N}$ : total number of respondents

A: Highest weight $=.925$

$\mathrm{W}$ : weight given to each factor by respondent

\section{RESUlt AND DisCUSSION}

After having the data analysis of the filled questionnaire survey, the factors are ranked. The table below shows the ranking of each factor.

\begin{tabular}{|c|c|}
\hline & RANKING OF FACTORS \\
\hline Rank & Factors \\
\hline 1 & Carelessness of worker \\
\hline 2 & Failure to use proper personal protective equipment \\
\hline 3 & Performing night work without providing adequate lighting \\
\hline 4 & Exposure of reinforcing bars \\
\hline 5 & Loading before setting \\
\hline 6 & Improper training programs \\
\hline 7 & Lack of supervision \\
\hline 8 & Lack of proper planning \\
\hline 9 & Failure to place proper barriers, railings and warning signs \\
\hline 10 & Placing the materials improperly near to the excavation edges \\
\hline 11 & Use of weak and deformed forms \\
\hline 12 & Excessive dust \\
\hline 13 & $\begin{array}{l}\text { Improper handling and storage of hazardous materials and } \\
\text { chemicals by untrained personnel }\end{array}$ \\
\hline 14 & Exceeding maximum lift of brickwork \\
\hline 15 & Lack of cleaning \\
\hline 16 & Transportation by improper vehicles \\
\hline 17 & Failure to locate underground facilities \\
\hline
\end{tabular}

The paper identified the factors affecting safety in construction sites. Among the identified factors, the Carelessness of worker contributes greater to accident rate. The results from literature review are confirmed by questionnaire surveys taken from construction sites. From the study, it was identified that the personnel factors of worker contributes primarily to accidents and incidents. 


\section{REFERENCES}

[1] Asgard T, Orgensen L (2019), Health and Safety in Early Phases of Project Management in Construction, Procedia,Computer Science, 164;343-349

[2] Gunduz M, Birgonul M T, Ozdemir M(2018); Development of a Safety Performance Index Assessment Tool by Using Structural Equation Model for Construction sites; Automation in Construction;85; 424-434

[3] Gunduz M, Ahsan B (2018) Construction Safety Assessment Through Frequency Adjusted Importance Index; International Journal of Industrial Ergonomics ; 64;155-162

[4] Guo H, Yu Y, Skitmore M (2017) Visualization Technology- Based Construction Safety Management; Automation in Construction 73,135144.

[5] Hola B, Nowobuski T, Szer I, Szer J (2017) Identification of Factors Affecting The Accident Rate in Construction Industry; proceedings of, 208:35-42
[6] Ladewski B J, Al-Bayati A J (2019); Quality and Safety Management practices: The theory of quality management approach ; Journal of Safety Research , 69,193-200

[7] Mahamoudi S, Ghasemi F, Mohammadfam I, Soleimani E (2014) Framework for Continuous Assessment and Improvement of Occupational Health and Safety Issues in Construction Companies; Safety and Health at work, 5,3,125-130

[8] Mohammadi A, Tavakolan M, Khosravi Y (2018); Factors influencing safety performance on construction projects; Safety Science 409; 382-397

[9] Sawacha E, Naoum S, Fong D (1999) Factors Affecting Safety Performance on Construction Sites; International Journal of Project Management; $17,5,309-315$

[10] Tam C M, Zeng S X, Deng Z M (2004) Identifying Elements of Poor Construction Safety Mangement in China; Safety Science 42; 569-586 